\title{
Las disputas por los territorios en los albores del Estado nación: la frontera oriental de Corrientes durante la segunda mitad del siglo $\mathrm{XIX}^{*}$
}

\begin{abstract}
Resumen
La organización del Estado nacional argentino implicó una significativa transformación de la forma en que los Estados provinciales habían configurado su territorio durante la primera mitad de siglo XIX a partir de la existencia de fronteras abiertas. Este artículo tiene como objetivo reconstruir las distintas posturas y argumentos que se pusieron en juego y que delinearon la definición de la configuración territorial de la provincia de Corrientes durante la segunda mitad del siglo XIX. Si bien las dirigencias correntinas no alcanzaron sus anhelos de incorporar la región de las Misiones bajo la jurisdicción provincial, el análisis de diversas fuentes permite evidenciar los puntos de tensión con respecto a cuál era la mejor forma de desarrollo para los territorios fronterizos y, a su vez, cómo el Congreso nacional se constituyó en un ámbito privilegiado para arbitrar las heterogéneas posturas políticas y determinar pautas de acción para los espacios disputados.
\end{abstract}

Palabras clave: Argentina, Corrientes, frontera, derecho territorial, parlamento.

Referencia para citar este artículo: BRESSAN, Raquel Valeria. (2017). "Las disputas por los territorios en los albores del Estado nación: la frontera oriental de Corrientes durante la segunda mitad del siglo XIX". En Anuario de Historia Regional y de las Fronteras. 22 (2). pp. 71-98.

Raquel Valeria Bressan: Becaria postdoctoral del CONICET . Doctora en Ciencias Sociales (Universidad Nacional de General Sarmiento/Instituto de Desarrollo Económico), Argentina. Magíster en Investigación Histórica de la Universidad de San Andrés). Profesora Universitaria en Historia (Universidad Nacional de General Sarmiento). Investigadora docente concursada del Instituto de Ciencias de la Universidad de General Sarmiento, profesora asistente de la asignatura Historia Argentina I (Instituto de Ciencias). Correo electrónico: bressanrv@gmail.com y vbressan@ungs.edu.ar. Código ORCID: 0000-0003-0662-3842.

\footnotetext{
* El presente artículo es resultado de la investigación para mi tesis doctoral Dinámicas e interacciones de los elencos políticos del Litoral de los Ríos durante la emergencia del sistema político y del Estado nacional: obras de infraestructura y organización territorial, 1862-1883, la cual contó con financiación de una beca doctoral del CONICET, Argentina.
} 


\title{
Territorial Disputes at The Dawn of The Nation State: The Eastern Border of Corrientes During The Second Half of the Nineteenth Century
}

\begin{abstract}
The construction of the Argentine state unfolded within a political environment where provincial boundaries were formulated out of largely open frontiers. This paper seeks to explore this situation for the case of Corrientes and it rebuilt different positions and arguments about how boundaries must be defined during the second half past of 19 th century, a period in which the province struggled (and failed) to incorporate the Missions territory under its jurisdiction. The analysis of various approaches to this questions permits a broader understanding of how Argentine politicians hoped to develop borderland spaces in more general terms and how the national Congress sometimes acted as referee or mediator among contending factions.
\end{abstract}

Keywords: Argentina, Corrientes, Border, Territorial Rights, Parliament.

\section{Disputas sobre territórios na aurora do Estado- nação: a fronteira oriental de Corrientes durante a segunda metade do século XIX}

\section{Resumo}

A organização do Estado nacional argentino implicou uma significativa transformação na forma em que os Estados provinciais haviam configurado seu território durante a primeira metade do século XIX, a partir da existência de fronteiras abertas. Este artigo pretende reconstruir as distintas posturas e argumentos que se colocaram e que delinearam a definição da configuração territorial da província de Corrientes durante a segunda metade do século XIX. Ainda que as diligências de Corrientes não alcançaram seus anseios de incorporar a região das Misiones sob a jurisdição provincial, a análise de diversas fontes permite evidenciar os pontos de tensão com respeito a qual era a melhor forma de desenvolvimento para os territórios fronteiriços e como o Congresso Nacional se constituiu em um âmbito privilegiado para arbitrar as posturas politicas heterogêneas e determinar pautas de ação para os espaços disputados.

Palavras-chave: Argentina, Corrientes, fronteira, lei territorial, parlamento. 


\section{Introducción}

Las historias nacionales otorgaron al territorio una cualidad preexistente y natural que comulgaba con la idea de una nación también preexistente, invisibilizando, así, los conflictos, los consensos y las diversas acciones que incidieron en la conformación territorial de los Estados ${ }^{1}$. Desde hace varias décadas, la renovación en la historia, en la geografía crítica y en la geopolítica como, asimismo, el intercambio metodológico entre estas disciplinas y también con los enfoques provistos por la antropología, la economía y la sociología, complejizaron la mirada y las formas de interrogar este proceso de conformación espacial. El territorio y sus delimitaciones dejaron de ser datos inmutables y pasaron a ser concebidos como una construcción, el resultado de un conjunto de procesos sociales. Es desde esta mirada que se ha estudiado la conformación de los límites internacionales -los movimientos e intercambios fronterizos; la incidencia de los procesos bélicos; las estrategias diplomáticas- y analizado las interacciones en las fronteras internas -el rol de las sociedades indígenas; las formas de ocupación de la tierra; las estructuras socioeconómicas y las prácticas y tradiciones políticas- como la organización jurídico administrativa de estos espacios ${ }^{2}$.

Dentro de esta extensa y rica producción son escasos los trabajos que analizan las disputas entre los gobiernos provinciales y el gobierno nacional por la definición de las fronteras internas y el rol que desempeñaron las nuevas instituciones liberales, como el Congreso, en la construcción de estas definiciones ${ }^{3}$. Se debe tener en cuenta que a partir de las revoluciones de independencia se produjo una alteración de las jerarquías territoriales preexistentes y una fragmentación de las entidades político-

\footnotetext{
${ }^{1}$ Una reflexión crítica a esa mirada en Palacios, Marcos. "América Latina: travesías hacia la nación moderna", en Palacios, Marcos (comp.), La unidad nacional en América Latina, del regionalismo a la nacionalidad (México: El Colegio de México, 1983), pp. 11-20 y Magnoli, Demetrio. O corpo da pátria. Imaginação geográfica y política externa no Brasil, 1808-1912 (São Paulo: Moderna, 1997), pp. 45-47.

${ }^{2}$ La bibliografía referida a esta temática es sumamente extensa. A modo de ejemplo: Areces, Nidia. "Regiones y Fronteras. Apuntes desde la Historia”, en Revista Andes, núm. 10, Salta, Universidad Nacional de Salta, 1999; Banzato, Guillermo y Lanteri, Sol. "Forjando la frontera. Políticas públicas y estrategias privadas en el Río de la Plata, 1780-1860", en Historia Agraria, núm. 43, 2007; Schmit, Roberto. "La construcción de la frontera decimonónica en la historiografía rioplatense", en Mundo Agrario, vol. VIII, núm. 16, 2008; Vangelista, Chiara. "Poderes locales en territorios de frontera: el caso de Mato Grosso (Brasil) en el siglo XIX”, en Dalla Corte, Gabriela, et al (coord.), Poder local, poder global en América Latina (Barcelona: Universidad de Barcelona, 2008), pp. 357-364; Garavaglia, Juan Carlos y Gautreau, Pierre. Mensurar la tierra, controlar el territorio. América Latina, siglos XVIII-XIX (Rosario: Prohistoria, 2011); Morales Raya, Eva. "La triple frontera latinoamericana: relaciones y conflictos interestatales entre Argentina, Brasil y Paraguay, siglos XIX y XX", en Morales Raya, Eva, et al (coord.), La frontera argentino paraguaya ante el espejo (Barcelona: Universidad de Barcelona, 2012), pp. 19-42; Dorfman, Adriana y Benedetti, Alejandro. "Presentación al dossier: Fronteras y movilidades", en Revista Territorio y Transporte, núm. 9, Buenos Aires, Universidad de Buenos Aires, 2013, pp. 1-10; Benedetti, Alejandro y Salizzi, Esteban. "La frontera en la construcción del Estado argentino", en Revista Colombiana de Geografia, vol. XXIII, núm. 2, Bogotá, Universidad Nacional de Colombia, 2013, pp. 122-138; Favaro, Orietta y Iuorno, Graciela (coords.). Dosier: Reflexiones en torno a los estudios sobre Territorios Nacionales, http://historiapolitica. com/dossiers/territorios/ (30 de julio de 2016).

${ }^{3}$ Allende, Andrés. "La polémica de 1869 sobre la delimitación de las provincias y territorios nacionales argentinos", en Investigaciones y Ensayos, núm. 42, 1992, pp. 57-112; Vitor, Marcos Gregório. "A emancipação negociada: os debates sobre criação da província do Paraná e o sistema representativo imperial, 1843”, em Revista Brasileira de Historia, vol. XXXV, núm. 69, São Paulo, 2015, pp. 319-341.
} 
administrativas ${ }^{4}$. En el Río de la Plata las provincias constituyeron "el primer fruto estable del derrumbe del imperio español" y, durante la primera mitad de siglo XIX, funcionaron como verdaderos Estados soberanos cuyas relaciones se articularon en torno al derecho internacional vigente 5 . Dentro de este contexto, las provincias incorporaron en forma paulatina los espacios considerados desiertos y, a su vez, desarrollaron prácticas y objetivos institucionales y políticos en base a la existencia de fronteras abiertas. Sin embargo, la constitución del Estado nacional implicó el desarrollo de nuevas dinámicas institucionales y políticas con respecto a la ocupación y la definición de las fronteras externas e internas.

En el presente trabajo analizamos las disputas entabladas entre los gobiernos provinciales y el gobierno nacional con respecto a los límites provinciales y a la potestad sobre territorios que ambos consideraban bajo su jurisdicción. En particular, focalizamos nuestro interés en las discusiones entre Corrientes y el Ejecutivo nacional por el territorio de Las Misiones y en los mecanismos institucionales e informales que se pusieron en juego para definir la configuración territorial de la provincia.

La región de las Misiones que se ambicionaba ubicar tanto bajo la esfera provincial como la nacional formaba parte de un espacio mayor atravesado por los ríos Iguazú, Uruguay y Paraná, considerado estratégico para el comercio y la vinculación de los pueblos en la cuenca del Plata. Ya desde la etapa colonial y a lo largo del siglo XIX, esta área representó un espacio a veces de convivencia y otras veces de disputa pero que también incluía extensas zonas poco conocidas lo cual dificultaba la definición o la aplicación de los límites establecidos en los diversos tratados negociados ${ }^{6}$. Los Estados nacionales formados en el siglo XIX incorporaron los pactos coloniales en las negociaciones iniciadas en la década de 1850. En 1857 se revisó las condiciones estipuladas por el tratado de San Idelfonso pero la inestable situación política entre

\footnotetext{
${ }^{4}$ Murilo de Carvalho, José. "Federalismo y centralización en el imperio brasileño", en Carmagnani, Marcello (coord.), Federalismos latinoamericanos: México, Brasil, Argentina (México: El Colegio de México, 1993), pp. 51-80; Timothy, Anna. Forging Mexico, 1821-1835 (Nebraska: University of Nebraska, 2001), pp. 98-138; Almario, Oscar. "Anotaciones sobre las provincias del Pacífico sur durante la construcción temprana de la República de la Nueva Granada, 1823-1857”, en Anuario de Historia Regional y de las Fronteras, vol. VI, núm. 1, Bucaramanga, Universidad Industrial de Santander, 2001, pp. 120-166; Serrano Ortega, José Antonio. Jerarquía territorial y transición política. Guanajuato, 1790-1836 (México: El Colegio de Michoacán/Instituto Mora, 2001); Martins, Herbert. “A fragmentação do território brasileiro: a criação de novos estados no Brasil”, em Caderno CRH, núm. 35, Salvador, 2001, pp. 263-288.

${ }^{5}$ Chiaramonte, José Carlos. "La cuestión regional en el proceso de gestación del estado nacional argentino"..., pp. 51-86.

${ }^{6}$ Durante el periodo colonial se celebraron dos significativos tratados entre las coronas españolas y portuguesas en pos de definir el dominio territorial de la región. En 1750 se firmó el Tratado de Madrid por el cual España cedía los territorios ocupados por las Misiones Jesuíticas en la margen oriental del río Uruguay a cambio de la ciudad de Colonia de Sacramento. La llamada guerra guaranítica que se desató como consecuencia del tratado y los lentos avances realizados por las comisiones demarcadoras determinaron la anulación de este tratado. Recién en 1777 se llegó a un nuevo acuerdo por el cual España conservaba los pueblos misioneros del Uruguay y Portugal cedía sus posesiones en las márgenes del río de la Plata. Maeder, Ernesto. "Los problemas de límites entre España y Portugal. Primera parte, 1494-1763", en Cuadernos Docentes, núm. 4, Chaco, IIGHI, 1986; Maeder, Ernesto. "Los problemas de límites entre España y Portugal. Segunda parte, 1764-1809”, en Cuadernos Docentes, núm. 5, Chaco, IIGHI, 1987; Heinsfeld, Adelar. Fronteira Brasil/Argentina (Passo Fundo: Méritos, 2007).
} 
la Confederación Argentina y el Estado de Buenos Aires impidieron su ratificación. Asimismo, el control de Paraguay sobre la región del Alto Paraná y sobre la navegación del río Uruguay chocaba contra los intereses de Brasil y Argentina de extender su dominio y potenciar la explotación forestal y de yerba mate en la región misionera y los intercambios comerciales con la libre navegación del río Paraguay ${ }^{7}$. Finalizada la Guerra de la Triple Alianza desde Argentina y Brasil se desplegaron un conjunto de medidas, no siempre articuladas, para avanzar sobre la región misionera. Así desde el oriente y el occidente se realizaron viajes exploratorios para obtener datos y construir una cartografía más eficiente; se fundaron pueblos y colonias y se elaboraron distintos proyectos para la navegación a vapor y la instalación de vías férreas. Luego de varios intentos de resolver el conflicto limítrofe por la vía diplomática, recién en 1895 y mediante la arbitración de Estados Unidos, se fijó que la línea divisoria entre ambos países se constituía a través de los ríos Pepirí Guazú y San Antonio ${ }^{8}$.

Consideramos que el estudio de los debates por la región de las Misiones entre fines de la década de 1870 y principios de 1880, un momento en que los límites entre la Argentina y Brasil aún se hallaban en proceso de definición, resulta relevante para avanzar en los procesos de construcción de los Estados latinoamericanos durante el siglo XIX. En este sentido, el análisis del proceso de configuración territorial de Corrientes nos permite comprender las tensiones y los mecanismos institucionales en la construcción de las fronteras internas y, a la vez, entender qué concepciones sustentaron determinadas estrategias de administración territorial como medio de garantizar la jurisdicción argentina en las zonas fronterizas en disputa con otros países.

\section{La expansión territorial de Corrientes en la región oriental}

El proceso de expansión de las fronteras que se desplegó en la región del Litoral al finalizar la etapa revolucionaria fue impulsado por un conjunto de políticas institucionales que buscaban incorporar nuevas tierras especialmente para el desarrollo de una ganadería extensiva. A partir de fines de la década de 1820, la provincia de Corrientes comenzó a extender sus fronteras orientales al incorporar bajo su jurisdicción parte de los quince pueblos que integraban las denominadas Misiones

\footnotetext{
${ }^{7}$ Brezzo, Liliana y Figallo, Beatriz. La Argentina y el Paraguay: de la guerra a la integración (Rosario: Pontificia Universidad Católica Argentina, 1999); Doratioto, Francisco. "La política del Imperio del Brasil en relación al Paraguay, 1864-1872”, en Richard, Nicolás; Capdevila, Luc y Boidin, Capucine (Dir.). Les guerres du Paraguay (París: Colibris, 2005), pp. 33-47; Whigham, Thomas. La Guerra de la Triple Alianza (Asunción: Taurus, 2011), tomo I.

${ }^{8}$ Mantilla, Manuel. Crónica histórica de la provincia de Corrientes (Buenos Aires: Espiase, 1929), tomo II; Heredia, Edmundo. "Historiografía de las relaciones argentino brasileñas", en Anuario de Estudios Americanos, vol. LIII, núm. 2, Sevilla, SCIC, 1996, pp. 267-284; Otero, Delia. "Articulación Estado-región de frontera en el área de Misiones o Palmas", en Cuadernos de Historia. Serie Economía y Sociedad, núm. 5, Córdoba, Universidad Nacional de Córdoba, 2002, pp. 141-160; Freitag, Liliane. Extremo oeste paranaense: historia territorial, região, identidade e (re) ocupação, (tesis doctoral), Universidad Estadual Paulista, 2007, pp. 23-77; Myskiw, Antonio. A fronteira como destino de viagem: a colônia militar da Foz do Iguaçu (1888-1907), (tesis doctoral), Universidad Federal Fluminense, 2009, pp. 74-114; Heinsfeld, Adelar. Fronteira e ocupação do espaço: a questão de Palmas com a Argentina e a colonização do vale do rio do Peixe (São Pablo: Perse, 2014), pp. 13-104.
} 
Las disputas por los territorios en los albores del Estado nación: la frontera oriental...

Occidentales la cuales comprendían la actual provincia de Misiones y el sector Este de Corrientes.

Mediante el Acuerdo del Cuadrilátero, suscrito por las provincias de Buenos Aires, Corrientes, Entre Ríos y Santa Fe en 1822, se había reconocido a Misiones como un Estado autónomo y fijado sus límites con Corrientes a lo largo del río Miriñay y su prolongación hacia el norte hasta la Tranquera de Loreto (actual Ituzaingó). Sin embargo, el desorden político y administrativo vivenciado en esta provincia a causa de las constantes incursiones brasileñas y paraguayas, propició que los indios misioneros de los pueblos de San Miguel, Loreto y La Cruz firmasen un acuerdo en el cual sometían sus territorios a la autoridad correntina con el fin de conservar la integridad de los mismos. De esta forma, el poblamiento correntino se extendió por los campos misioneros principalmente en el inmenso ángulo comprendido entre los ríos Uruguay y Miriñay hasta el río Aguapey, donde la república del Paraguay controló hasta la década de 1860 el puente terrestre ubicado entre el alto Paraná y el alto Uruguay que conectaba la localidad paraguaya de Itapúa con la brasileña de San Borja 9 .

En 1870 el desenlace de la Guerra del Paraguay reforzó las aspiraciones de la dirigencia correntina de incorporar el territorio de las Misiones Occidentales en su totalidad. Aunque era un área poco conocida, en el imaginario de este sector, las Misiones representaban enormes riquezas vírgenes a explotar que se hallaban bajo la amenaza de ser expropiadas por el avance de los brasileños. Para contrarrestar esta amenaza, se llevó a cabo desde los sucesivos gobiernos provinciales una política de fundación de pueblos combinada con el desarrollo de proyectos de infraestructura para la comunicación y el transporte que permitieran una articulación más fluida entre las nuevas áreas pobladas y los departamentos más antiguos.

Así, durante las décadas de 1860 y 1870 el establecimiento de líneas regulares de navegación a vapor en el Alto Paraná y el Alto Uruguay y la articulación de estas con las vías férreas y los caminos carreteros construidos en la frontera oriental de Corrientes y Entre Ríos dieron aliento a los nuevos pueblos situados en la costa del Alto Paraná al permitir su integración al dinámico circuito mercantil articulado a través del puerto entrerriano de Concordia. El aumento de la población en esta zona en forma, paralela al incremento de la explotación de la yerba mate y la madera de los bosques misioneros, motivó la creación del departamento de Candelaria y la designación del paraje de Trinchera de San José (actual Posadas) como ciudad cabecera del mismo ${ }^{10}$.

\footnotetext{
${ }^{9}$ Schaller, Enrique. "El proceso de distribución de la tierra en la provincia de Corrientes (1588-1895)", en Anuario del CEH, núm. 1, Córdoba, Instituto de estudios Históricos “Dr. Carlos A. Segreti”, 2001, pp. 5-87.

${ }^{10}$ Bressan, Raquel. "Interacciones de la política local, regional y nacional. Entre Ríos y Corrientes (18621880)", en Schmit, Roberto (ed.), Caudillos, política e instituciones en los orígenes de la Nación Argentina (Buenos Aires: UNGS, 2015), pp. 193-215.
} 
Figura 1. Evolución de los límites provinciales hasta 1871.

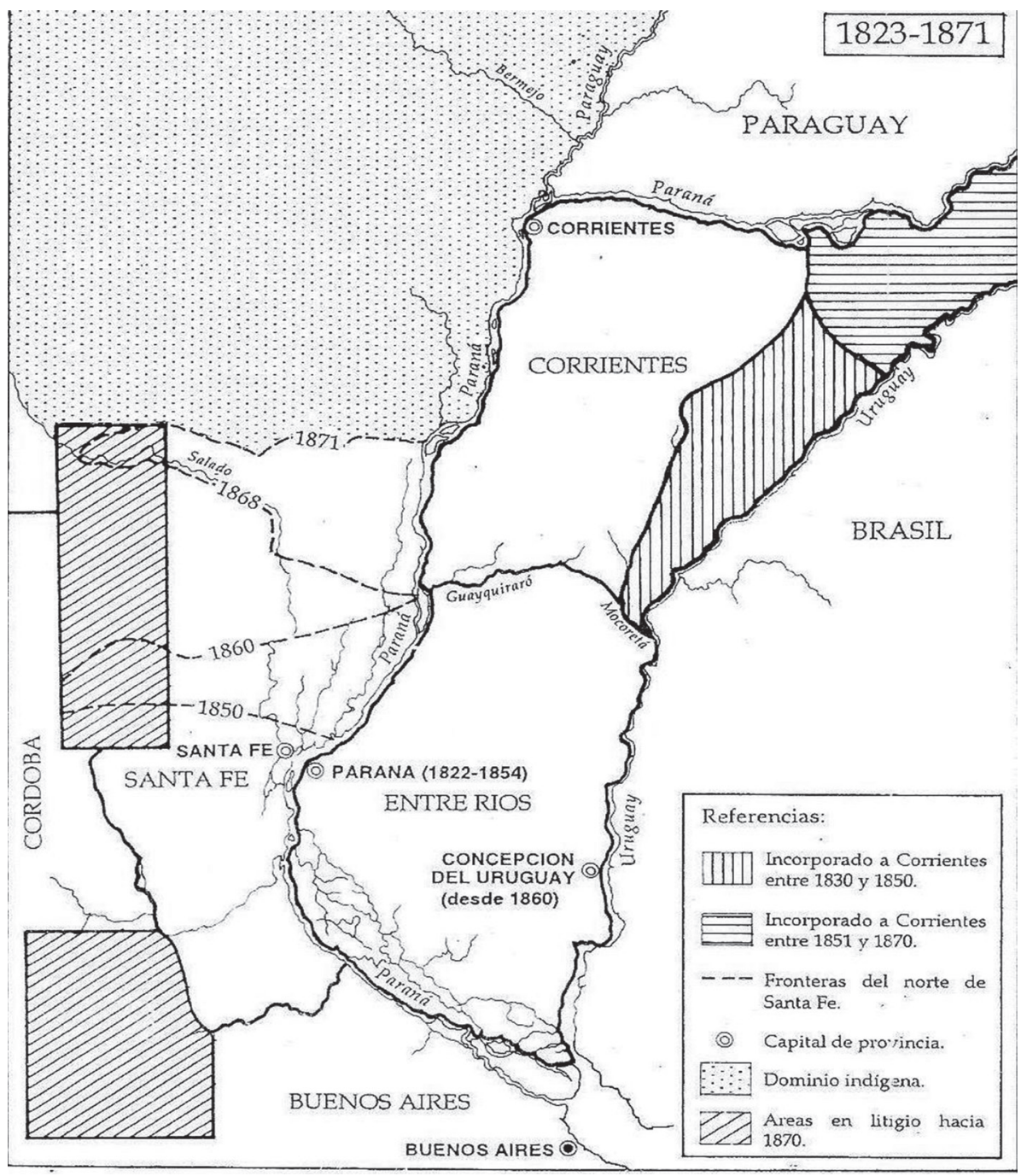

Fuente: Maeder, Ernesto y Gutiérrez, Ramón. Atlas histórico del nordeste argentino (Resistencia: Instituto de Investigaciones Geohistóricas/Universidad Nacional del Nordeste, 2003).

Si bien a lo largo de cuarenta años se incrementó notablemente el avance de la frontera oriental correntina sobre los territorios misioneros a través de la ocupación efectiva como se observa en la Figura 1; desde el punto de vista legal resultaban ínfimos los progresos en el recorrido para definir los límites de Corrientes y su derecho para incorporar estos territorios bajo su jurisdicción. Se debe tener en cuenta que en 1862 , con la sanción de la ley nacional número 28 , se había dado un primer paso en pos de la organización de los límites internos de la Argentina. En ella se determinaba que: "[...] todos los territorios existentes fuera de los limites, o posesión de las Provincias, son nacionales, aunque hubiesen sido enajenados por 
los Gobiernos Provinciales desde el $1^{\circ}$ de Marzo de 1853" $" 11$. Sin embargo, como al momento de sancionarse la ley existían reclamos jurisdiccionales de las provincias sin resolución también se incluyó un artículo que señalaba que se analizaría para cada caso la documentación presentada por las provincias para fijar sus límites. De esta forma, la ley asentó la concepción de dos unidades sub-nacionales: las provincias y los territorios nacionales. Pero a su vez, la inclusión de este artículo también propició un marco de incertidumbre sobre los espacios cuya jurisdicción estaba en disputa. Principalmente porque hasta 1881, si bien la Nación adscribía bajo su jurisdicción los denominados territorios nacionales, estos eran áreas marginales donde el Estado aún no había establecido cuáles eran y cómo se fijarían sus límites ni configurado las formas de estructuración administrativo-institucional que regirían en ellos.

A principios de 1870, Nicasio Oroño, senador por la provincia de Santa Fe, y Bartolomé Mitre, senador por la provincia de Buenos Aires presentaron dos proyectos en el Congreso donde planteaban que los límites debían ser fijados en base a accidentes geográficos o mediciones astronómicas, en tanto eran considerados criterios científicos y, por tal motivo, una forma adecuada para superar los conflictos que la cuestión de la delimitación había desencadenado en el país ${ }^{12}$. Frente a esta propuesta, un conjunto de senadores priorizaron la validez de los criterios históricos, conformados por la documentación colonial y del período de independencia y la posesión de hecho ${ }^{13}$. Juan Eusebio Torrent, senador por Corrientes y uno de los fervientes defensores del argumento histórico, consideró que estos debates presentaban una ocasión propicia para plantear el reclamo territorial de su provincia. Para ello reunió un corpus documental que respaldaba el reclamo sobre el territorio de las Misiones pero en el recinto legislativo se decidió postergar su tratamiento hasta la resolución de los límites internacionales ${ }^{14}$.

La rebelión política de 1872 que expulsó a los liberales del gobierno Correntino, sumada a los movimientos armados en la vecina Entre Ríos, provocaron un paréntesis en el interés de regularizar los límites provinciales ${ }^{15}$. Sin embargo, desde mediados de la década la definición del estatus jurídico de las Misiones comenzó a cobrar singular importancia tanto en la esfera provincial como en la nacional. En 1876 se aprobó el tratado de límites con Paraguay y, en el mismo año, se sancionó la ley nacional

\footnotetext{
${ }^{11}$ Congreso Nacional. Cámara de Diputados. Diario de Sesiones (en adelante CNCDDS), sesión del 17 de octubre de 1862 .

${ }^{12}$ Navarro Floria, Pedro. "La nacionalización fallida de la Patagonia Norte, 1862-1904", en Quinto Sol, núm. 7, 2003, pp. 61-91.

${ }^{13}$ Archivo Histórico de la Cámara de Diputados de la Nación (AHCDN), Proyecto de ley sobre límites interprovinciales, caja 11, expediente 17-D-1872.

${ }^{14}$ Congreso Nacional. Cámara de Senadores. Diario de Sesiones (en adelante CNCSDS), sesión del 14 de mayo de 1871; AHCDN, caja 11, exp. 17-D-1872; Archivo General de la provincia de Corrientes (AGPC), Correspondencia Oficial, tomo 262, Carta de Juan Eusebio Torrent a Juan Lagraña, Buenos Aires, 9 de septiembre de 1871 y Fondo Mantilla, Carta de Gregorio Pampín a Manuel Lagraña, 19 de mayo de 1877.

${ }^{15}$ A partir de 1872 el gobierno de la provincia quedó en manos del partido fusionista, el cual se dividiría luego en autonomistas y nacionalistas. Sobre las rebeliones en Corrientes y Entre Ríos. Sommariva, Luis. Historia de las intervenciones federales en las provincias (Buenos Aires: El Ateneo, 1931).
} 
número 817 de Inmigración y colonización. En ella se referían a los territorios nacionales de forma más específica, incluyendo a la región de Misiones dentro de los mismos, a la vez que indicaba la conveniencia de iniciar su colonización. Bajo esta premisa, el 27 de febrero de 1877 por decreto presidencial se concedió a Otto Rosse, como representante de una Sociedad Anónima de Colonización del Alto Uruguay, dos secciones de tierras en Misiones, en el espacio geográfico donde estuviera asentada la reducción de Mártires ${ }^{16}$.

Una parte de la dirigencia correntina, integrantes del denominado partido nacionalista, protestó enérgicamente desde la prensa local frente a lo que consideraban "un desconocimiento de los derechos que tiene la provincia al territorio" y que las medidas adoptadas por el ejecutivo nacional se orientaban a la "desmembración del territorio correntino" "17. En paralelo, los miembros del ejecutivo provincial comenzaron a tomar medidas concretas. En marzo el ministro de gobierno, Manuel Derqui, acordó con el presidente que no se otorgarían concesiones hasta que el Congreso fijara por ley los límites interprovinciales. Para sustentar el reclamo de Corrientes, el gobernador José Luis Madariaga creó el 5 de abril de 1877 una Comisión para organizar una colección de documentos probatorios de los derechos que asistían a la Provincia sobre el territorio de Misiones. El trabajo de la comisión, que completó la labor de Juan Eusebio Torrent, fue presentado en el mes de agosto de ese mismo año y se elevó al Congreso $^{18}$.

Sin embargo, la clara escisión política del elenco político correntino agregó una nueva variable que influiría notablemente en las disputas entre la Nación y la provincia por el territorio misionero. Los miembros de uno y otro partido poseían significativos contactos políticos a nivel nacional con los cuales respaldar su reclamo. Por ejemplo, el autonomista Manuel Derqui había sido designado Ministro Plenipotenciario en Paraguay y su labor para resolver en 1876 la cuestión de límites con Argentina había sido ampliamente reconocida. Asimismo, había estrechado lazos durante la década de 1870 con Dardo Rocha y Aristóbulo del Valle, senadores por Buenos Aires, y con Julio Roca, quien tenía una destacada trayectoria militar y sería elegido presidente en 1880. Por otra parte, Juan Eusebio Torrent, uno de los principales referentes del nacionalismo, había forjado desde la década de 1860 amistad con Bartolomé Mitre, al cual acompañó en la fórmula presidencial para la candidatura de 1874; con Rufino de Elizalde, Ministro de Relaciones Exteriores y Culto, y con los senadores por Santa Fe Nicasio Oroño y Joaquín Granel ${ }^{19}$.

\footnotetext{
${ }^{16}$ Colección de datos y documentos referentes a Misiones como parte integrante del Territorio de la Provincia de Corrientes hecha por una Comisión nombrada por el Gobierno de ella (Corrientes: Imprenta de La Verdad, 1877).

17 "La colonización de Misiones", en La Tribuna, Buenos Aires, 10 de enero de1878; AGPC, Fondo Mantilla, Carta de Manuel Derqui a los jueces de paz, Corrientes, 7 de mayo de 1877 y Archivo General de la Nación (AGN), Fondo Dardo Rocha, leg. 9, Cartas de José Luis Madariaga a Dardo Rocha, Corrientes, 15 de marzo y 11 de abril de 1877.

${ }^{18}$ Colección de datos y documentos referentes a Misiones..., Op Cit., pp. 27-29.

19 Bressan, Raquel. "Los legisladores nacionales correntinos: trayectorias, vínculos y capacidad de negociación (1869-1880)", en IV Jornadas Interdisciplinarias de Investigaciones Regionales. Enfoques
} 
Más allá que la incorporación de las Misiones a la jurisdicción correntina era un objetivo común de los sectores dirigentes de esa provincia y que junto a las medidas tomadas por el gobierno provincial se contaba con sectores influyentes para respaldar el reclamo, su tratamiento en el Congreso estuvo atravesado por las disputas por el control del poder a nivel local que se desplegaron en los últimos años de la década de 1870. En 1877 los autonomistas controlaban el poder ejecutivo y los nacionalistas dominaban las bancas en el Congreso nacional, a su vez, a fines de ese mismo año se debían renovar los cargos de gobierno. Dentro de este contexto, el tratamiento de la cuestión Misiones fue concebido como una estrategia para reforzar las posiciones de unos y otros en la contienda electoral. Los nacionalistas correntinos consideraron que aquel era el momento óptimo para instalar en la agenda parlamentaria de 1877 la cuestión de Misiones pero los autonomistas no compartían esta postura y se opusieron férreamente a que la cuestión se tratase ese año. Los miembros del ejecutivo provincial temían que los diputados nacionalistas se arrogasen el rédito de una resolución favorable en la cuestión Misiones, lo cual afectaría su posición de poder, la cual no estaba consolidada a nivel local, como se puede deducir del pedido de Severo Fernández, secretario general de gobierno, a Dardo Rocha:

Creo conveniente que el Congreso postergue este año el asunto Misiones, nuestros diputados son todos contrarios nuestros y han de tratar el asunto bajo el prisma político para procurar perjudicarnos aquí [...] Si el asunto Misiones se resolviese este año tendríamos infaliblemente la siguiente consecuencia: si ganamos nuestros diputados nacionales han de querer darse aires de victoriosos explotando su ardid y si perdemos (lo que no creo) han de decir que este gobierno ha sido el causante de la pérdida, como al principio dijeron ya que éramos nosotros los que entregábamos el territorio.

Si la cuestión se postergara para el año próximo, tendríamos ya representación nuestra en el Congreso, mejor que la actual, habrán cesado Díaz, Rivera y Lagraña, cuestión gobernador habrá pasado ya aquí y todo andará entonces sin cuidado $^{20}$.

Si bien los autonomistas lograron aplazar los debates, la coyuntura política de los años siguientes no fue tan auspiciosa. Las movilizaciones armadas que tuvieron lugar en la provincia, primero en 1878 a causa de la disputa por la elección del gobernador y en 1880 por la adhesión de Corrientes a la rebelión de Carlos Tejedor, aplazaron el tratamiento de la cuestión Misiones por un período mucho más largo que el que habían previsto los autonomistas correntinos. A ello se sumaba que la inestabilidad política imperante luego de estas movilizaciones y dos intervenciones nacionales, debilitó la posición de los sectores dirigentes correntinos dentro del juego de alianzas en la arena política nacional ${ }^{21}$.

para la Historia, Universidad Nacional de Cuyo, 2015.

${ }^{20}$ AGN, Fondo Dardo Rocha, leg. 9, Carta de Severo Fernández a Dardo Rocha, Corrientes, 27 de mayo de 1877.

${ }^{21}$ Bressan, Raquel. "Las repercusiones en Corrientes de la política de conciliación de partidos (1877-1880)", en Coordenadas. Revista de Historia Local y Regional, vol. III, núm. 1, Córdoba, Centro de Investigaciones Históricas de la Universidad Nacional de Río Cuarto, 2016. 


\section{La cuestión Misiones en el contexto nacional}

Durante la sesión de apertura del Congreso en 1881, el presidente Julio Argentino Roca remarcó en su mensaje la imperiosa necesidad de dictar una ley definitiva que determinase los límites de los territorios nacionales para que estos espacios se poblaran y se transformaran definitivamente bajo la acción fecunda de la industria. En este mensaje, Roca proponía seis espacios concretos que podían ser declarados nacionales: el Territorio del Pilcomayo, el Territorio del Bermejo, el Territorio del Gran Chaco, el Territorio de las Misiones, el Territorio de Las Pampas y el Territorio de Río Negro ${ }^{22}$.

De esta forma, se colocaba en primer plano la principal cuestión que el elenco correntino había arrastrado sin resolución desde la década de 1860 pero planteado desde un ángulo completamente distinto al de su enfoque: pues se integraba a las Misiones dentro de los espacios considerados desiertos y faltos de civilización a los cuales sólo el concurso de la nación podía integrarlos definitivamente a la República $\mathrm{y}$ al sendero del progreso.

Entonces, dentro del contexto nacional, debe comprenderse que la federalización del territorio de las Misiones no obedeció a un hecho aislado -si bien fue presentado sistemáticamente por algunos autores como una represalia concreta por la alianza de los liberales correntinos con Tejedor ${ }^{23}$ - sino que formaba parte de un programa de largo plazo que buscaba extender el control y la administración del orden nacional a todos los territorios considerados marginales como, asimismo, se proponía resolver y delinear en paz las fronteras con los países vecinos mediante acuerdos y arbitrajes.

Aquel proceso tuvo dos fases distintas, por un lado, se encontraban los pasos dados para constituir herramientas jurídicas que definieran los límites de los territorios que quedaban bajo potestad de la Nación y, por otro, lograr la ocupación rápida y concreta de esos territorios. Desde la presidencia de Nicolás Avellaneda, entre 1874 y 1880 , se buscó despejar la indefinición con respecto a los límites de los territorios bajo potestad nacional y se avanzó con pasos firmes en pos de la definición de los límites internacionales y en el inicio de las tareas de apropiación de los ámbitos que no estaban bajo dominio del Estado nacional, pasos que fueron continuados en el período siguiente. Dentro del conjunto de nuevas medidas que se llevaron a cabo se encontraban la ley de Inmigración y colonización de 1876 y las leyes número 576, 947 y 1149, que organizaban las gobernaciones del Chaco (1872), la Patagonia (1878) y de las Misiones (1881). En el sur, la campaña al desierto de 1879, permitió la incorporación de una ingente cantidad de tierras a la producción agropecuaria y logró afianzar la soberanía sobre la Patagonia que era disputada por Chile. En la frontera chaqueña se realizaron siete expediciones militares entre 1870 y 1884, cuyo objetivo era avanzar en una ocupación militar progresiva que se extendió en esta etapa hasta

\footnotetext{
22 "Mensaje presidencial", en La Tribuna Nacional..., Buenos Aires, 06 de junio de 1881.

${ }^{23}$ Gómez, Hernán. Los últimos sesenta años de democracia y gobierno en la provincia de Corrientes, (Corrientes: Imprenta del Estado, 1929) y Florencio Mantilla, Manuel. Crónica histórica de la provincia de Corrientes (Buenos Aires: Espiase, 1929).
} 
el río Bermejo. Aquellas acciones de ocupación militar fueron acompañadas por las gestiones llevadas a cabo en materia de política internacional. El tratado firmado en 1876 definió los límites con Paraguay y se fijó como línea divisoria el río Pilcomayo, aunque se postergó la resolución de la Villa Occidental que sería sometida a arbitraje norteamericano. Por otra parte, los acuerdos firmados con Chile en 1881 afirmaron los derechos de Argentina sobre la Patagonia oriental ${ }^{24}$.

El crecimiento y la expansión que se registró desde finales de la década de 1840 en la región de las antiguas Misiones Jesuíticas, tanto en términos económicos, demográficos y estratégicos, incrementó notablemente el interés y los conflictos por los derechos territoriales de esta zona fronteriza. La virulencia alcanzada por los pleitos en torno a la región de las Misiones, propició la celebración de varios tratados entre Argentina y Brasil que no pudieron ser ratificados ${ }^{25}$. Asimismo, desde la creación de la provincia de Paraná en 1853, sus dirigencias buscaron consolidar la idea que la provincia era estratégica para la defensa de los límites con Paraguay y Argentina y el gobierno nacional debía dirigir sus recursos para avanzar en la colonización de la frontera. Si bien este objetivo no se logró en un principio, luego de la Guerra de la Triple Alianza se comenzó a discutir diversos planes para abrir caminos hacia la margen izquierda del río Paraná. Entre ellas se destacaba la autorización del gobierno imperial al Barón de Mauá para que realizara en 1876 estudios para la construcción de una vía férrea que ligara a Curitiba con Miranda y la instalación de líneas de vapor en los ríos Paraná, Ivaí, Brillante y Mondego. Además, frente a lo que las autoridades paranaenses concebían como una explotación ilegal de los yerbales en los campos de Eré, Piquirí e Iguazú por parte de los correntinos, comenzaron a instalarse desde 1878 colonias militares como estrategia colonizadora ${ }^{26}$.

Frente a las dificultades para resolver la definición de límites, tanto desde el lado argentino como el brasileño se había optado por avanzar en la ocupación directa del área de frontera. Pero desde fines de 1870 en el ejecutivo nacional argentino se fortaleció paulatinamente la convicción que la mejor respuesta para resolver el problema jurisdiccional se centraba en colocar este territorio bajo el control federal ${ }^{27}$.

\footnotetext{
${ }^{24}$ Gómez, Hernán. Historia de la Gobernación nacional del Chaco (Buenos Aires: Graff, 1939) y Bandieri, Susana. "Ampliando las fronteras: la ocupación de la Patagonia", en Lobato, Mirta (Dir.), El progreso, la modernización y sus límites (Buenos Aires: Sudamericana, 2000), pp. 87-122.

${ }^{25}$ Buchbinder, Pablo. Caudillos de pluma y hombres de acción (Buenos Aires: UNGS-Prometeo, 2004).

${ }^{26}$ Myskiw, Antonio. A fronteira como destino de viagem..., pp. 81-111.

${ }^{27}$ Zouví, Susana. "La federalización de Misiones”, en Favaro, Orietta y Iuorno, Graciela (coords.). Dosier. Reflexiones en torno a los estudios sobre Territorios Nacionales..., Op Cit.
} 
Figura 2. Área de litigio entre Argentina y Brasil.

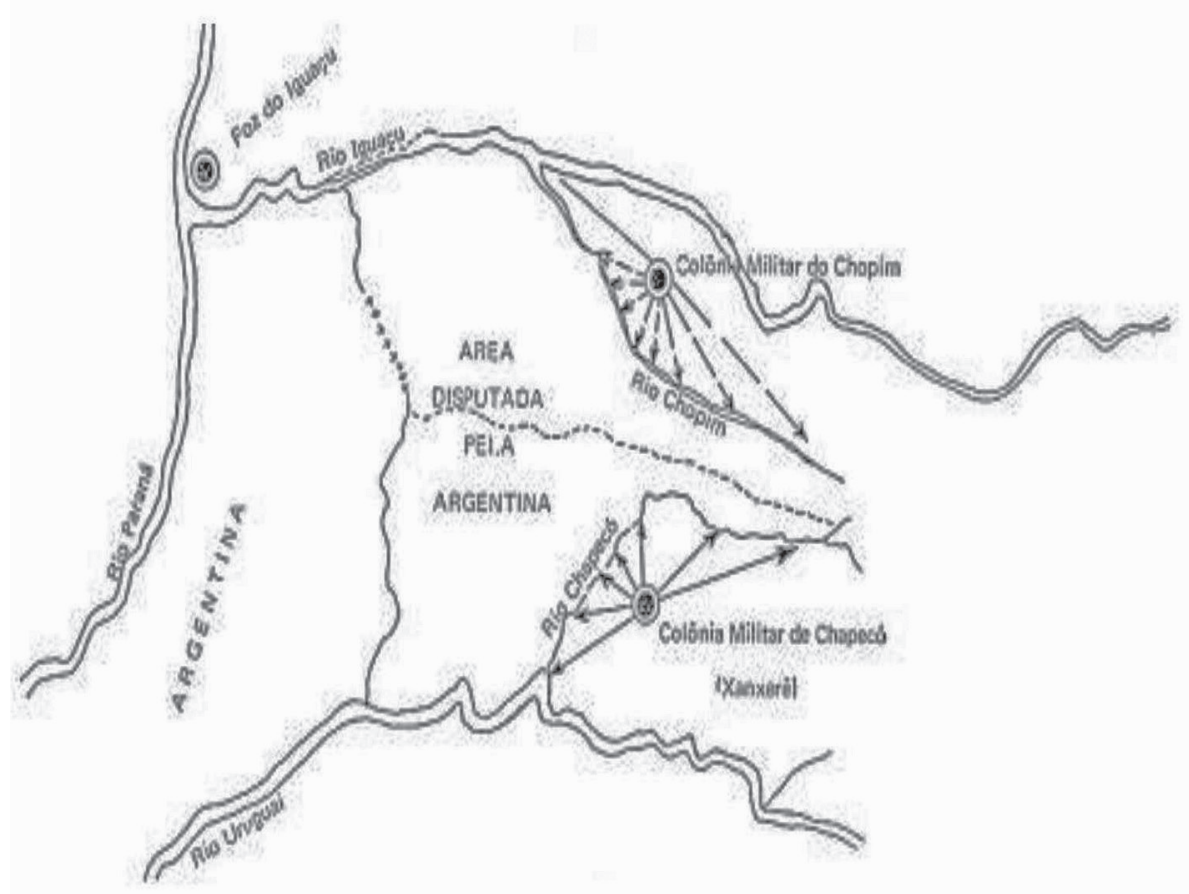

Fuente: Boutin Leónidas. "Colonias militares na Provincia do Paraná”, en Separata do Boletim HIGEP, núm. 33, Curitiba, 1977.

En suma, la federalización de Misiones no puede comprenderse cabalmente aislada de aquel contexto general de expansión de la ocupación efectiva, tanto desde Brasil como de Argentina, de los territorios considerados marginales y del proceso de construcción de un marco jurídico de definición de los límites territoriales. Sin embargo, el territorio de Misiones presentaba particularidades que las diferenciaban muy claramente de los otros cinco espacios visualizados como territorios nacionales. Las jurisdicciones administrativas creadas en esta zona durante la etapa colonial y el período revolucionario, la disolución de los Pueblos de las Misiones y la incorporación de algunos de ellos a la jurisdicción correntina durante la primera mitad de siglo XIX, sumado a la creación de nuevos departamentos, constituyeron un proceso y un factor que dificultó su visualización dentro del conjunto de áreas vacías de civilización, el cual se puso en juego en las disputas por la definición de su estatus ya fuera como parte de la provincia de Corrientes o como territorio nacional. 
Las disputas por los territorios en los albores del Estado nación: la frontera oriental...

Figura 3. Departamentos creados por la cámara legislativa correntina en el territorio de Misiones.

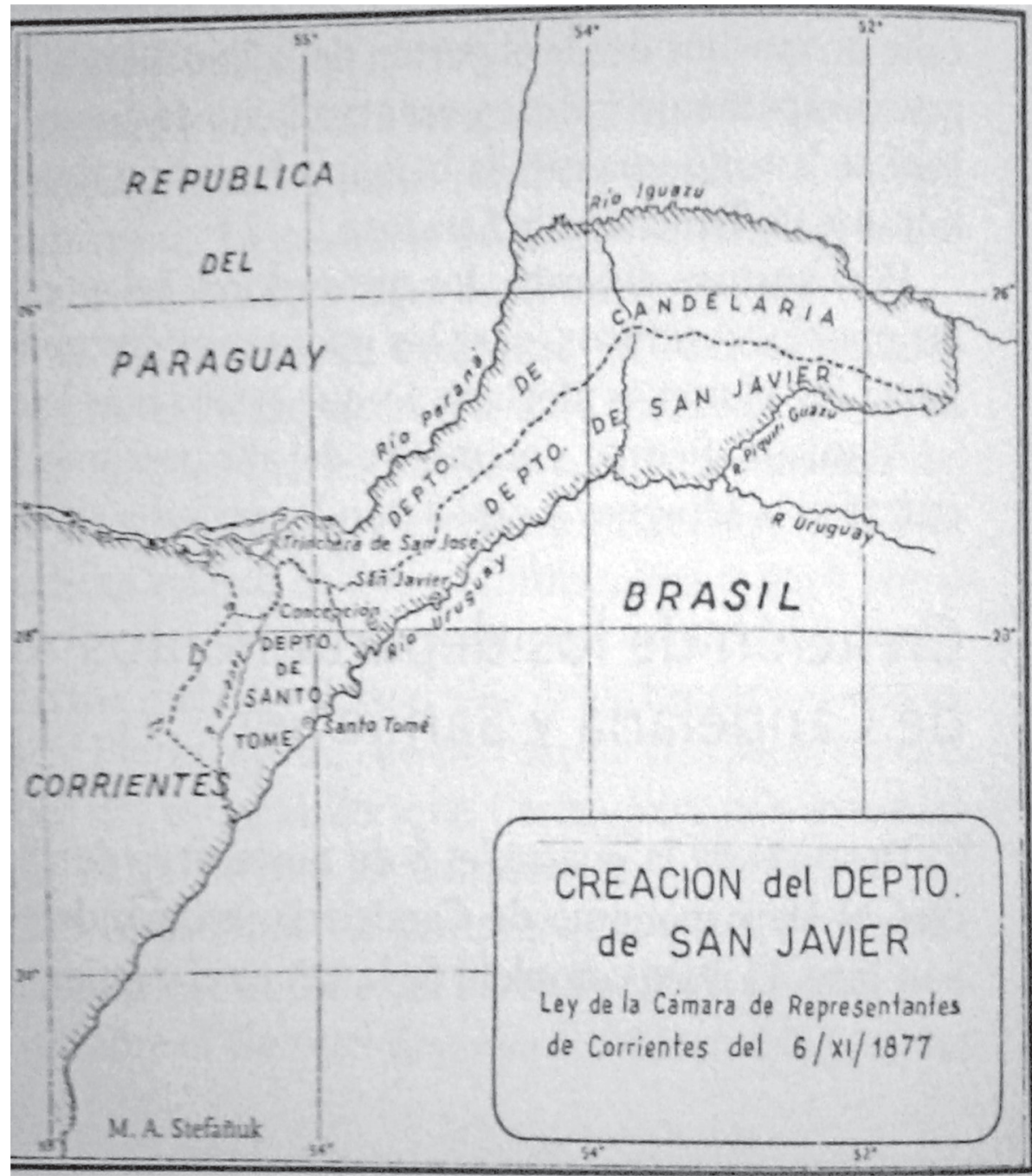

Fuente: Stefañuk, Miguel Ángel. Evolución de la cartografía de Misiones (Posadas: Montoya, 1991).

\section{Los debates en la prensa y en el Congreso}

El Congreso desempeñó un rol decisivo en la configuración territorial de las provincias y de los territorios nacionales en tanto los límites propuestos para unos y otros debían ser aprobados en este recinto legislativo. Como señaló Gianfranco Poggi, el Congreso no transmite simplemente los impulsos originados en otras partes, sino que es el ámbito por excelencia de discusión y de procesos vitales para la toma de 
decisiones ${ }^{28}$. En este sentido, consideramos que el rol de esta institución no se basó en cubrir con un manto de legitimidad los proyectos de límites diseñados previamente por el ejecutivo nacional, si no que estos se delinearon a partir de los debates y las negociaciones entabladas en las Cámaras. Asimismo, se debe tener en cuenta que las argumentaciones de los legisladores se inscribían dentro de un horizonte republicano acerca de las funciones del Congreso que ya se había delineado durante la etapa de la Confederación y se consolidó en las décadas siguientes: las leyes debían procurar un proceso de transformación y modernización socioeconómica que garantizaran el bienestar general ${ }^{29}$.

¿Cuál era la solución que garantizaría el bienestar general en la cuestión de límites? La prensa también desempeñó un rol significativo en la construcción de una respuesta a esta pregunta. La prensa decimonónica constituía una de las principales herramientas para la discusión de todos los desafíos vinculados a la constitución y administración de los Estados nacionales y a través de sus páginas se buscaba legitimar determinadas posturas al interior de estas disputas ${ }^{30}$. Por este motivo, previamente al análisis de los debates parlamentarios presentamos cómo, a través de los artículos publicados en La Tribuna Nacional y en La Nación, se buscó consolidar una determinada imagen, desde la cual se respaldaría los reclamos del ejecutivo nacional o de Corrientes con respecto a la región de Misiones.

En julio de 1881, el presidente Roca emitió un mensaje al Congreso en el que se planteaba la necesidad de declarar territorio nacional a la región de Misiones, la cual, bajo la indebida apropiación de Corrientes, se había subsumido en el atraso y el aislamiento. Desde mayo y hasta finales de diciembre, cuando se sancionó la ley de federalización del territorio, la prensa porteña se posicionó a favor y en contra de esta postura con el objetivo de legitimarla o deslegitimarla e influir en los debates en el Congreso. Dentro del frondoso periodismo porteño, La Tribuna Nacional y La Nación dedicaron numerosos editoriales a lo largo de estos meses en relación con el tratamiento de la cuestión Misiones ${ }^{31}$.

\footnotetext{
${ }^{28}$ Poggi, Gianfranco. El desarrollo del Estado moderno (Buenos Aires: Universidad Nacional de Quilmes, 1997).

${ }^{29}$ Lanteri, Ana Laura. Se hace camino al andar. Dirigencias e instituciones nacionales en la Confederación, Argentina 1852-1862 (Rosario: Prohistoria, 2015).

${ }^{30}$ La bibliografía sobre la prensa decimonónica es sumamente extensa. A modo de ejemplo: Alonso, Paula (comp.), Construcciones impresas. Panfletos, diarios y revistas en la formación de los estados nacionales en América Latina, 1820-1920 (Buenos Aires: FCE, 2003).

${ }^{31}$ Para el periodo analizado, que comprende las disputas que se sostuvieron desde mayo a diciembre de 1881, en la provincia de Corrientes se publicaban El Autonomista y La Provincia. Si bien la elección de La Tribuna Nacional y La Nación obedece a que representaban a cada una de las posturas que disputaba la jurisdicción del territorio de las Misiones y que, a su vez, estos periódicos buscaban erigirse en prensa nacional por la gran circulación que tenían, no se ha podido incorporar también una reconstrucción de las posturas e imágenes que sostuvieron los periódicos correntinos en esta cuestión ya que no se encuentran disponibles ejemplares de los mismos ni en los archivos nacionales ni tampoco en los provinciales. Sobre la prensa correntina: Mantilla, Manuel. Bibliografía periodística de la provincia de Corrientes (Corrientes: Amerindia, 2007 [1887]).
} 
La Tribuna Nacional era el diario oficial, salió a la venta por primera vez en octubre de 1880, y constituyó la principal herramienta para legitimar las medidas y posturas tomadas desde el gobierno, explicitaba sus objetivos y se defendía de sus adversarios ${ }^{32}$. A través de sus páginas, se construyó una imagen de severo deterioro del territorio de las Misiones, cuyo gran potencial productivo era desperdiciado. Aquella imagen era presentada por el diario como resultado de un proceso extendido a lo largo del siglo XIX, por el cual la zona se había despoblado, perdiendo todo vestigio de civilización; y por ello, a pesar de poseer un pasado muy distinto, era equiparable al desierto patagónico o al chaqueño. Más aún, la provincia de Corrientes en "su ambición por las grandes extensiones territoriales", se había constituido en un obstáculo para su progreso y en cincuenta años de "indebida posesión" nada había realizado para transformar la realidad de aislamiento y retraso de uno de los espacios más ricos de la Argentina. Por tanto, la conclusión a la que arribaba el impreso era sin duda imperativa: solo en las manos de la Nación era posible corregir este proceso ${ }^{33}$. Los relatos construidos sobre las Misiones sustentaron la idea de un territorio desarticulado de la República, donde imperaba la anarquía y el distanciamiento de la ley, hecho que se reconocía a partir de una única actividad existente: el contrabando de yerba y de ganado.

La metáfora del desierto remitía a todas las áreas desconocidas, de las cuales se carecía de conocimiento geográfico, dominadas por la naturaleza salvaje y habitadas por los pueblos indígenas. Desierto significaba entonces vacío de civilización, una construcción simbólica que acompañó los procesos de expansión y consolidación territorial de los estados nacionales latinoamericanos ${ }^{34}$. Aunque desde el discurso de La Tribuna Nacional se buscó englobar a la región de las Misiones en su totalidad bajo la categoría de desierto, sólo el área en litigio con Brasil podía ser ubicaba dentro de estos parámetros. Por este motivo, La Nación combatió tanto esta imagen como la que se presentaba sobre la gestión realizada por la provincia de Corrientes como argumentos para federalizar el territorio misionero. El diario de Bartolomé Mitre se había erigido durante la década de 1870 en un baluarte desde el cual los nacionalistas correntinos buscaron solventar su postura ante diversas situaciones y con el cierre de la mayoría de sus periódicos desde la revolución de 1880, sumado al exilio de este sector, se potenció el rol del periódico como ámbito donde ellos podían desplegar su pluma $^{35}$.

\footnotetext{
32 Alonso, Paula. "La Tribuna Nacional y Sud-América: tensiones ideológicas en la construcción de la Argentina moderna en la década de 1880", en Alonso, Paula (comp.), Construcciones impresas..., pp. 203-243.

${ }^{33}$ Estas ideas se repitieron constantemente en los editoriales que fueron redactados por Olegario Andrade, director del diario. La Tribuna Nacional, Buenos Aires, 06 de junio de 1881; 08 de junio de 1881; 10 de junio de 1881; 12 de junio de 1881; 13 de junio de 1881; 22 de septiembre de 1881 y 17 de diciembre de 1881.

${ }^{34}$ Amado, Janaina. "Região, sertão, nação", en Estudos Históricos, vol. VIII, núm. 15, Río de Janeiro, 1995, pp. 145-151; Moraes, Antonio. Ideologías Geográficas (Sao Paulo: Hucitec, 1996); Lois, Carla. "Desierto y territorio: imágenes decimonónicas del Gran Chaco argentino", en Mundo de antes, núm. 2, Tucumán, Instituto de Arqueología de la UNT, 2001, pp. 97-117.

${ }^{35}$ Bressan, Raquel, Op Cit.
} 
En aquel periódico, desde el editorial y desde los artículos especiales redactados por colaboradores correntinos, se presentaron tres ejes de discusión frente a la propuesta del Ejecutivo nacional. En primer lugar, se argumentaba que la existencia de un territorio nacional pensado como medio para resucitar el esplendor de las Misiones representaba una idea con la que nadie podía estar disconforme. Ahora bien, desde sus páginas se cuestionaba que este fuera el mejor medio para alcanzar este objetivo. Si una de las bases de su ruina era el atraso demográfico, del cual se responsabilizaba a Corrientes, el gobierno nacional tampoco había demostrado obtener buenos resultados en el objetivo de sanear el problema de la escasez de población y arraigar la inmigración con el sistema de colonias. Por el contrario, la mala administración de las colonias, la falta de supervisión adecuada y el abuso de varios agentes nacionales afectaron los intereses de los colonos y de la Nación, llevando al fracaso a varios de estos emprendimientos ${ }^{36}$.

En segundo lugar, precisamente, se denunciaba el falso retrato de la ruina de la región y se señalaban como evidencia los datos estadísticos de los censos nacionales y provinciales referentes a población, tierras distribuidas en enfiteusis, las propiedades urbanas y rurales, el número de cabezas de ganado, la producción de yerba y la actividad comercial que corroboraban esta denuncia y desmontaban las afirmaciones del ejecutivo:

En 1753, época del esplendor de Misiones, bajo la administración jesuítica, tenían estas, según Azara, 10.394 familias con 43.089 habitantes. ¿Qué población tiene, según el censo provincial levantado en marzo de 1879 por la ley de la legislatura de Corrientes?

Esas ruinas y desiertos, según el Mensaje, tenían hace dos años 32.472 habitantes que llegaran hoy ya por lo menos a $35.000 \ldots$

En 1854, el Gobierno de Corrientes mandó a levantar el Censo de Misiones y dio este resultado: 4.425 habitantes. En 1857 ascendió la población a 5.734, según el censo oficial, llegando en los 24 años siguientes a 35 mil, lo que no tiene parecido en América del sur.

¿Puede llamarse a un territorio con semejante población, ruinas y desiertos, como dice el Mensaje del Gobierno? ${ }^{37}$

El tercer eje se centraba en una crítica con respecto a cómo el gobierno provincial se había desenvuelto en la cuestión Misiones. El régimen instalado en 1880, era conducido por "un gobernante más ignorante que Andresito" y donde no se respetaba el sistema "representativo, republicano y federal ni siquiera en la forma". Desde los artículos se explicaba que se daba una relación entre el gobierno nacional y provincial a partir de la cual a cambio de obediencia el presidente daba libertad para cometer toda clase de irregularidades. Bajo este contexto, señalaba el periódico que debía ser entendido el camino tomado en la cuestión Misiones, donde el gobierno correntino

\footnotetext{
${ }^{36}$ La Nación, Buenos Aires, "Las colonias", 07 de julio de1881 y 20 de octubre de 1881.

${ }^{37}$ La Nación, Buenos Aires, "Las Misiones", 09 de julio de 1881.
} 
Las disputas por los territorios en los albores del Estado nación: la frontera oriental...

controlado por los autonomistas, además de no oponerse a que se nacionalizara un territorio que consideraban por derecho bajo la jurisdicción de la provincia, se entregaron tierras a los funcionarios y los oficiales a precios irrisorios:

\begin{abstract}
Es posible que una cosa parecida les haya dicho [Roca] hoy a sus amigos de esta [por Corrientes] con motivo del asunto Misiones; por ejemplo, les habrá dicho -"Salven su dignidad ante sus propios comprovincianos, dando un manifiesto cualquiera, y no me combatan ni resistan al proyecto; y repártanse entre ustedes también la tierra expropiada antes que vaya a la acción nacional". Esa más o menos ha de ser la moral del negocio ${ }^{38}$.
\end{abstract}

Por lo tanto, los redactores del diario de Bartolomé Mitre plantearon efusivamente que si el gobierno de Corrientes no podía defender los derechos legítimos de la provincia, eran los legisladores nacionales quienes debían asumir esa causa.

En los debates realizados en el Congreso, el reconocimiento que la región de Misiones no era un desierto sino que existían áreas ocupadas por Corrientes fue central para orientar la discusión con respecto a cómo se debían fijar los límites entre provincias y territorios nacionales y en qué forma debía proceder el Congreso en estos casos. Todos los legisladores acordaban en la rigurosidad con que el tema debía ser tratado en tanto, al referirse a la primera ley especial de límites que el Congreso dictaba para una provincia, sentaría un precedente para dirimir cuestiones similares que se presentarían en el futuro ${ }^{39}$. En 1878, ya se había sancionado una ley para delimitar los territorios nacionales del sur y que comprometía también los límites de las provincias de Buenos Aires, Córdoba, Mendoza y San Luis. Sin embargo, a diferencia de la cuestión Misiones, esta ley se basó en un acuerdo transaccional en el que la Nación cedía a las provincias las tierras más ricas y cercanas a la frontera sur, que aún no estaban ocupadas en ese momento, a cambio de que abandonasen sus pretensiones sobre tierras más lejanas ${ }^{40}$.

El proyecto presentado por el Ejecutivo nacional, en cambio, incluía como límite oeste del territorio nacional el río Aguapey, por lo tanto, se consideraba parte del nuevo territorio la totalidad de los espacios incorporados por la provincia desde la mitad de siglo y los departamentos de Paso de los Libres, Santo Tomé, La Cruz creados desde la década de 1830 por el avance de la frontera oriental (ver Figura 1). La legislatura correntina elaboró un contundente manifiesto presentado al Congreso frente a lo que consideraba un avasallamiento del ejecutivo nacional sobre los derechos de su soberanía local "[...] desde que es público que en faz de toda la Nación Corrientes tiene posesiones por medio de sus poblaciones, industrias y propiedades de sus hijos, mucho más adelante del Aguapeí al Este"41. La comisión evaluadora del proyecto

\footnotetext{
${ }^{38}$ La Nación, Buenos Aires, "Las tierras de Misiones", 27 de julio de 1881.

${ }^{39}$ CNCSDS, sesión del 16 de septiembre de 1881.

${ }^{40}$ La ley sancionada era la número 947: Allende, Andrés. "Las delimitaciones territoriales dispuestas por la ley de 5 de octubre de 1878", en Congreso Nacional de Historia sobre la Conquista del Desierto, General Roca, 1979.

${ }^{41}$ Manifiesto que la H.C.L. de la provincia de Corrientes dirige al H.C. de la Nación sosteniendo los
} 
decidió reformularlo y fijar como límite oriental de Corrientes el río Uruguay y los arroyos Chimirai y Pindapoi y la línea más directa que los uniese ${ }^{42}$.

En los debates en el senado, el sanjuanino Rafael Irgarzábal señaló que la Constitución había arrogado al Congreso la función de determinar los límites interprovinciales y que la ley de 1862 establecía que pertenecía al dominio provincial todos los territorios ocupados hasta el 1 de mayo de 1853. De tal forma, todos los territorios no ocupados por las provincias hasta esa fecha pertenecían a la Nación y ese era el criterio que se debería utilizar en cuestión de límites. En el caso particular de Corrientes, el proyecto modificado otorgaba una zona mayor a la que obtendría bajo ese criterio y, así, se compensaba los esfuerzos de la provincia invertidos en el desarrollo de la zona misionera ${ }^{43}$.

El representante por Buenos Aires, Carlos Pellegrini refutó la postura de su colega al plantear que la Constitución reconocía la existencia de territorios nacionales en calidad de territorios despoblados. Por lo tanto, al fijar los límites de una provincia se debía considerar todos los territorios por ella poblados al momento de ese procedimiento. Si el Congreso se aferraba a los límites existentes en el año de 1862 pondría un límite al acrecentamiento del progreso. Asimismo, el senador porteño consideraba inconstitucional el proyecto de creación del territorio nacional de Misiones porque representaba la federalización de un espacio provincial.

En la cámara de diputados, Felipe Yofré argumentaba que uno de los criterios a tener en cuenta eran los propios límites y territorios reconocidos por las provincias en sus Constituciones. En el caso particular de Corrientes, su Carta magna de 1852 no fijaba sus límites y no reconocía ninguna sección electoral más que Restauración en el territorio de las Misiones. Por lo tanto, resolvía el diputado cordobés que si en 1853 “"...] el territorio de Misiones no era una provincia ni pertenecía a Corrientes, según lo demostrado, si por nuestro derecho público todo lo que no es territorio de la Provincia es territorio Nacional, se sigue forzosamente que Misiones pertenece a la Nación" $" 44$. No obstante, en forma similar a la de Pellegrini, reflexionaba que el Congreso no podía establecer los límites de las provincias en forma absoluta y arbitraria porque esto significaría desconocer la historia de las provincias, pero, a diferencia del legislador bonaerense, Yofré ponderaba que el proyecto formulado en el senado era justo ya que reconocía bajo la jurisdicción de Corrientes una porción mayor de territorios que los que esta poseía en 1853.

El segundo eje incorporado a los debates en ambas cámaras, expuesto principalmente por los legisladores correntinos y avalado por varios senadores y diputados de otras provincias, se centró en la injusticia que representaba para Corrientes la creación

derechos de la Provincia al Territorio de Misiones parte integrante de la misma (Corrientes: Imprenta El Autonomista, 1881), pp. 5-6.

${ }^{42}$ CNCSDS, sesión del 16 de septiembre de 1881.

${ }^{43}$ CNCSDS, sesión del 16 de septiembre de 1881.

${ }^{44}$ CNCDDS, sesión del 12 de diciembre de 1881. 
del Territorio Nacional de Misiones. Este reclamo se inscribía dentro de lo que se consideraba una relación justa entre los que la provincia aportaba a la Nación y lo que percibía en retribución de esta. En este sentido, los senadores Miguel Gelabert y Santiago Baibiene y el diputado José Luis Madariaga, planteaban que Corrientes siempre había defendido con recursos propios las fronteras de la Nación e incluso durante la Guerra del Paraguay, los correntinos habían impedido el avance de las tropas paraguayas durante varios meses sin el auxilio de las fuerzas nacionales; sus puertos contribuían a incrementar los tesoros de la nación y sus rentas fiscales habían formado parte del presupuesto de Guerra que permitió extender el dominio nacional al sur y al norte del país. Poco era lo recibido a cambio de los sacrificios de Corrientes y arbitraria era la conducta con la distribución del progreso, como planteaba Madariaga:

No se me dirá que la provincia de Santa Fe ha progresado únicamente con sus propios elementos. No, señor presidente, es debido a la mano generosa y protectora de la Nación y del Congreso argentino [...]

La provincia de Entre Ríos se encuentra más o menos en las mismas condiciones que la de Santa Fe a 16 horas de los grandes mercados de Buenos Aires y Montevideo [...] llevado lo que consume de estos grandes centros con un recargo de solo el 405 por ciento; mientras que lo que se lleva a Corrientes por la misma vía tiene un recargo del 10,20 y hasta el 30 por ciento de recargo debido a las largas distancias y a los inconvenientes que ofrece el tránsito por que la Nación no ha gastado ni un solo peso para mandar a construir una sola alcantarilla en su camino y mucho menos un puente sobre sus caudalosos ríos que bañan toda la provincia ${ }^{45}$.

No obstante, este reclamo no fue utilizado para combatir el proyecto de federalización. Esta línea discursiva tenía como objetivo dejar asentado que la renuncia de las aspiraciones de Corrientes al territorio de Misiones constituía uno más de los sacrificios hechos por la provincia -sin recibir nada a cambio- para el crecimiento de la República, en tanto, como señalaban Gelabert y Madariaga, no se desconocía el derecho de la Nación sobre la región despoblada de Misiones, pero los límites demarcados por el proyecto quitaban a la jurisdicción provincial dos poblaciones importantes, Candelaria y San Javier, con siete mil habitantes.

Consideramos relevante subrayar los planteos y las acciones de los legisladores correntinos en estos debates. La postura en el Congreso no era homogénea con respecto al proyecto de federalización pero en este escenario, el reclamo acerca de la injusticia cometida con Corrientes en la cuestión Misiones y la falta de recompensas otorgadas a esta a cambio de sus sacrificios, no fueron utilizados por los legisladores correntinos como argumentos para cambiar el rumbo de la discusión y pedir la colaboración de la Nación para el desarrollo de Misiones como parte integrante de la provincia. Por el contrario, con la excepción de Baibiene, todos los legisladores de Corrientes votaron a favor del proyecto.

${ }^{45} C N C D D S$, sesión del 12 de diciembre de 1881. 
Durante las sesiones en el Congreso no fue posible alinear a los legisladores tras la propuesta planteada por Pellegrini. Las fuertes discusiones entre Gelabert y Baibiene, responsabilizando a las acciones del partido del que cada uno era miembro por el caos en que se hallaba sumergida la provincia; el mal manejo del tesoro provincial y las graves irregularidades en la venta de las tierras fiscales en la región de Misiones, constituyeron elementos que favorecieron el convencimiento que, incluso con la ayuda de la Nación, Corrientes resultaría incapaz de desarrollar y controlar las zonas Misioneras designadas para su nacionalización ${ }^{46}$.

La ley del 22 de diciembre de 1881 fijó como límites para Corrientes el río Paraná al oeste; el Alto Paraná al norte; los arroyos Chimirai y Pindapoi y el río Uruguay al este y los ríos Mocoretá y Guayquiraró al sur (ver Figura 4.). De modo tal, que los límites fijados por el Congreso no respondían a lo proyectado desde el ejecutivo nacional ni comulgaban con las expectativas de largo aliento de los correntinos. Por el contrario, en un contexto en que varías provincias se hallaban en proceso de definir su configuración territorial, estos límites expresaban una postura intermedia donde los congresistas equilibraron los intereses de las provincias en general, al reconocer como parte de Corrientes los territorios que esta había incorporado en la margen oriental del río Uruguay, con los intereses de la Nación al incluir dentro del territorio nacional los dos departamentos, Candelaria y San Javier, que se encontraban en la zona de litigio con Brasil.

Por último, debemos señalar que la legislatura provincial dictó el 22 de agosto de 1882 una ley que cedía, frente a la solicitud del ejecutivo nacional, una superficie de 632 kilómetros cuadrados que incluía el pueblo de Posadas para que este se convirtiese en la capital del nuevo territorio nacional de Misiones. El 16 de junio de 1883 se trató en el Congreso el petitorio del presidente para la aprobación de esta cesión. En esta ocasión, Aristóbulo del Valle argumentó la inconstitucionalidad de la donación, que no podía ser realizada por una legislatura, ni tampoco nacionalizar un territorio que por ley había sido declarado parte de una provincia. Sin embargo, con el respaldo de esta donación por parte del propio ejecutivo correntino y de los legisladores provinciales y nacionales, triunfó el pedido del presidente. Así finalmente, con la ley nacional 1437, el territorio provincial se modificó una vez más y se determinó en este proceso sus límites actuales ${ }^{47}$ (ver Figura 4.).

\footnotetext{
${ }^{46}$ CNCSDS, sesiones del 16 y 17 de septiembre de 1881 .

${ }^{47}$ CNCSDS, sesión del 16 de agosto de 1883.
} 
Las disputas por los territorios en los albores del Estado nación: la frontera oriental...

Figura 4. Límites de Corrientes establecidos por las leyes de 1881 y 1883.

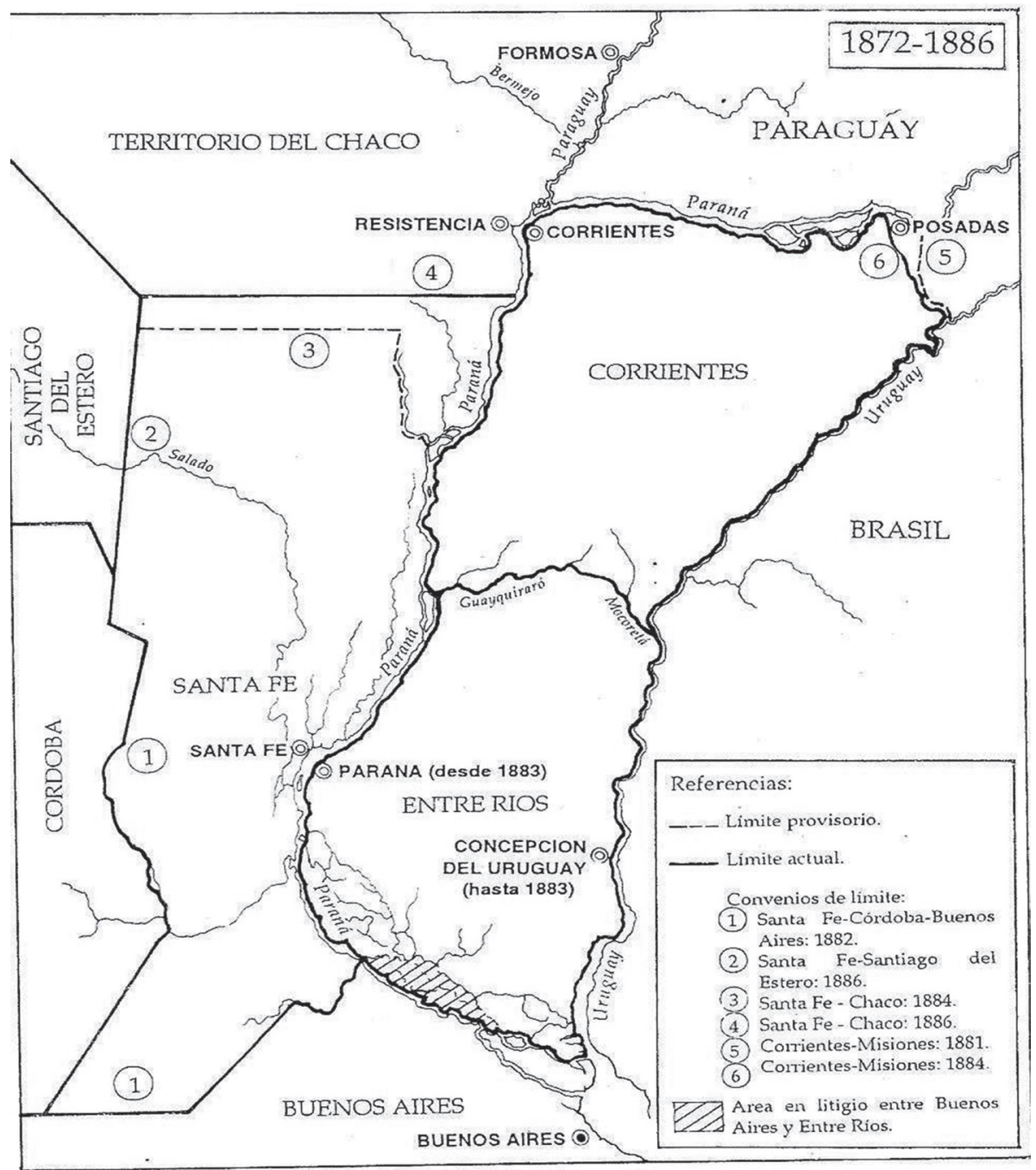

Fuente: Maeder, Ernesto y Gutiérrez, Ramón. Atlas histórico del nordeste argentino (Resistencia: Instituto de Investigaciones Geohistóricas/Universidad Nacional del Nordeste, 2003).

\section{Conclusiones}

Durante la primera mitad de siglo XIX y en un contexto de fronteras abiertas, las provincias extendieron o redujeron su área de jurisdicción principalmente en base a su capacidad para poblar y resguardar los nuevos territorios que se incorporaban con el avance de la frontera. La sanción de la Constitución nacional impuso cierto límite a este proceso al concebir a las zonas que no se hallaban bajo posesión provincial como dependientes de la jurisdicción de la Nación. Pero, dentro de un contexto 
donde el propio Estado nacional se hallaba en proceso de construcción, las provincias continuaron con la extensión de sus fronteras y, como en el caso de Corrientes, se buscó el desarrollo de políticas públicas que impulsaran la incorporación paulatina de nuevos territorios, incluso con aportes de recursos financieros y técnicos de la Nación como por ejemplo para la subvención de las líneas de navegación a vapor o la construcción de ferrocarriles. Así, de forma similar a las prácticas que tuvieron lugar en la provincia de Paraná en Brasil, se ratificaban los derechos territoriales en las zonas fronterizas a partir de la asistencia del gobierno nacional para lograr el poblamiento efectivo y la integración de estos territorios a la provincia. Estas prácticas, sin embargo, encontraron un punto final en los últimos años de la década de 1870 y el surgimiento de tensiones entre el gobierno nacional y el de Corrientes.

Bajo este complejo proceso donde las prácticas concretas se distanciaban de la pauta legal, el Congreso se erigió como el árbitro para dirimir las disputas por los derechos territoriales de la Nación y de las provincias pero incluso en este ámbito las posturas no eran homogéneas. Un factor central que se consideró, apelando a distintos argumentos expresados tanto en la prensa como en los debates, refería a qué jurisdicción brindaría mejores posibilidades de control y desarrollo para estos territorios. La federalización de los diversos territorios durante la década de 1880 indica el triunfo de la idea que el florecimiento de estas áreas sería posible sólo bajo la jurisdicción nacional. A su vez, también da cuenta del cambio de una etapa, de un momento de construcción del Estado nacional a uno de consolidación. Sin embargo, también resulta necesario pensar qué características había adquirido la dinámica política local de cada provincia que no permitió la consolidación entre los legisladores nacionales que ese florecimiento también podría ser alcanzado bajo la jurisdicción provincial con la asistencia del gobierno nacional como se había llevado a cabo en los años anteriores.

\section{Fuentes}

\section{Fuentes primarias}

\section{Archivos}

Archivo General de la Nación (AGN), Sección Archivos Particulares, Fondo Dardo Rocha.

Archivo General de la provincia de Corrientes (AGPC), Correspondencia Oficial.

Archivo General de la provincia de Corrientes (AGPC), Fondo Mantilla.

Archivo Histórico de la Cámara de Diputados de la Nación (AHCDN).

\section{Publicaciones periódicas}


Las disputas por los territorios en los albores del Estado nación: la frontera oriental...

Diario La Nación, Buenos Aires, 1881.

Diario La Tribuna, Buenos Aires, 1878, 1881.

\section{Libros}

Gobierno de la Provincia de Corrientes. Colección de datos y documentos referentes a Misiones como parte integrante del Territorio de la Provincia de Corrientes hecha por una Comisión nombrada por el Gobierno de ella. Corrientes: Imprenta de La Verdad, 1877.

Congreso Nacional. Cámara de Senadores. Diario de Sesiones de 1871. Buenos Aires: Imprenta de la Honorable Cámara de Diputados, 1929.

Congreso Nacional. Cámara de Senadores. Diario de Sesiones de 1881. Buenos Aires: la República, 1882.

Congreso Nacional. Cámara de Senadores. Diario de Sesiones de 1883. Buenos Aires: la República, 1884.

Poder Legislativo de Corrientes. Manifiesto que la H.C.L. de la provincia de Corrientes dirige al H.C. de la Nación sosteniendo los derechos de la Provincia al Territorio de Misiones parte integrante de la misma. Corrientes: Imprenta El Autonomista, 1881.

\section{Fuentes secundarias}

\section{Libros}

Brezzo, Liliana y Figallo, Beatriz. La Argentina y el Paraguay: de la guerra a la integración. Rosario: Pontificia Universidad Católica Argentina, 1999.

Buchbinder, Pablo. Caudillos de pluma y hombres de acción. Buenos Aires: UNGSPrometeo, 2004.

Garavaglia, Juan Carlos y Gautreau, Pierre. Mensurar la tierra, controlar el territorio. América Latina, siglos XVIII-XIX. Rosario: Prohistoria, 2011.

Gómez, Hernán. Los últimos sesenta años de democracia y gobierno en la provincia de Corrientes. Corrientes: Imprenta del Estado, 1929.

Gómez, Hernán. Historia de la Gobernación nacional del Chaco. Buenos Aires: Graff, 1939.

Heinsfeld, Adelar. Fronteira e ocupação do espaço: a questão de Palmas com a Argentina e a colonização do vale do rio do Peixe. San Pablo: Perse, 2014. 
Heinsfeld, Adelar. Fronteira Brasil/Argentina. Passo Fundo: Méritos, 2007.

Lanteri, Ana Laura. Se hace camino al andar. Dirigencias e instituciones nacionales en la Confederación, Argentina 1852-1862. Rosario: Prohistoria, 2015.

Magnoli, Demetrio. O corpo da pátria. Imaginação geográfica y política externa no Brasil, 1808-1912. São Paulo: Moderna, 1997.

Maeder, Ernesto y Gutiérrez, Ramón. Atlas histórico del nordeste argentino. Resistencia: Instituto de Investigaciones Geohistóricas/Universidad Nacional del Nordeste, 2003.

Mantilla, Manuel Florencio. Crónica histórica de la provincia de Corrientes. Buenos Aires: Espiase, 1929.

Mantilla, Manuel. Bibliografía periodística de la provincia de Corrientes. Corrientes: Amerindia, 2007 [1887].

Mata, Sara y Areces, Nidia (coords.). Historia Regional. Estudios de caso y reflexiones teóricas. Salta: Universidad Nacional de Salta, 2006.

Moraes, Antonio. Ideologías Geográficas. Sao Paulo: Hucitec, 1996.

Poggi, Gianfranco. El desarrollo del Estado moderno. Buenos Aires: Universidad Nacional de Quilmes, 1997.

Serrano Ortega, José Antonio. Jerarquía territorial y transición política. Guanajuato, 1790-1836. México: El Colegio de Michoacán/Instituto Mora, 2001.

Sommariva, Luis. Historia de las intervenciones federales en las provincias. Buenos Aires: El Ateneo, 1931.

Stefañuk, Miguel Ángel. Evolución de la cartografía de Misiones. Posadas: Montoya, 1991.

Timothy, Anna. Forging Mexico, 1821-1835. Nebraska: University of Nebraska, 2001.

Whigham, Thomas. La Guerra de la Triple Alianza. Asunción: Taurus, 2011, tomo I.

\section{Capítulos de libros}

Alonso, Paula. "La Tribuna Nacional y Sud-América: tensiones ideológicas en la construcción de la Argentina moderna en la década de 1880", en Alonso, Paula (comp.), Construcciones impresas. Panfletos, diarios y revistas en la formación de los estados nacionales en América Latina, 1820-1920. Buenos Aires: FCE. 
Las disputas por los territorios en los albores del Estado nación: la frontera oriental...

Bandieri, Susana. “Ampliando las fronteras: la ocupación de la Patagonia”, en Lobato, Mirta (Dir.), El progreso, la modernización y sus límites. Buenos Aires: Sudamericana, 2000 .

Bressan, Raquel. "Interacciones de la política local, regional y nacional. Entre Ríos y Corrientes (1862-1880)", en Schmit, Roberto (ed.), Caudillos, política e instituciones en los orígenes de la Nación Argentina. Buenos Aires: UNGS, 2015.

Chiaramonte, José Carlos. "La cuestión regional en el proceso de gestación del estado nacional argentino", en Palacios, Marcos (comp.), La unidad nacional en América Latina, del regionalismo a la nacionalidad. México: El Colegio de México, 1983.

Doratioto, Francisco. "La política del Imperio del Brasil en relación al Paraguay, 1864-1872”, en Richard, Nicolás; Capdevila, Luc y Boidin, Capucine (Dir.), Les guerres du Paraguay. Paris: Colibris, 2005.

Morales Raya, Eva. "La triple frontera latinoamericana: relaciones y conflictos interestatales entre Argentina, Brasil y Paraguay, siglos XIX y XX”, en Morales Raya, Eva, et al (coords.), La frontera argentino paraguaya ante el espejo. Barcelona: Universidad de Barcelona, 2012.

Murilo de Carvalho, José. "Federalismo y centralización em el imperio brasileño", en Carmagnani, Marcello (coord.), Federalismos latinoamericanos: México, Brasil, Argentina. México: El Colegio de México, 1993.

Palacios, Marcos. "América Latina: travesías hacia la nación moderna”, en Palacios, Marcos (comp.), La unidad nacional en América Latina, del regionalismo a la nacionalidad. México: El Colegio de México, 1983.

Vangelista, Chiara. "Poderes locales en territorios de frontera: el caso de Mato Grosso (Brasil) en el siglo XIX”, en Dalla Corte, Gabriela, et al (coords.), Poder local, poder global en América Latina. Barcelona: Universidad de Barcelona, 2008.

\section{Artículos en revistas}

Allende, Andrés. "La polémica de 1869 sobre la delimitación de las provincias y territorios nacionales argentinos”, en Investigaciones y Ensayos, núm. 42, 1992.

Almario, Oscar. "Anotaciones sobre las provincias del Pacífico sur durante la construcción temprana de la República de la Nueva Granada, 1823-1857”, en Anuario de Historia Regional y de las Fronteras, vol. VI, núm. 1, 2001.

Amado, Janaina. "Região, sertão, nação”, en Estudos Históricos, vol. VIII, núm. 15, 1995. 
Areces, Nidia. "Regiones y Fronteras. Apuntes desde la Historia", en Revista Andes, núm. 10, 1999.

Banzato, Guillermo y Lanteri, Sol. "Forjando la frontera. Políticas públicas y estrategias privadas en el Río de la Plata, 1780-1860”, en Historia Agraria, núm. 43, 2007.

Benedetti, Alejandro y Salizzi, Esteban. "La frontera en la construcción del Estado argentino", en Revista Colombiana de Geografia, vol. XXIII, núm. 2, 2013.

Bressan, Raquel. "Las repercusiones en Corrientes de la política de conciliación de partidos (1877-1880)", en Coordenadas. Revista de Historia Local y Regional, vol. III, núm. 1, 2016.

Boutin Leónidas. "Colonias militares na Provincia do Paraná”, en Separata do Boletim HIGEP, núm. 33, 1977.

Dorfman, Adriana y Benedetti, Alejandro. "Presentación al dossier: Fronteras y movilidades", en Revista Territorio y Transporte, núm. 9, 2013.

Heredia, Edmundo. "Historiografía de las relaciones argentino brasileñas", en Anuario de Estudios Americanos, vol. LIII, núm. 2, 1996.

Lois, Carla. "Desierto y territorio: imágenes decimonónicas del Gran Chaco argentino", en Mundo de antes, núm. 2, 2001.

Maeder, Ernesto. "Los problemas de límites entre España y Portugal. Primera parte, 1494-1763”, en Cuadernos Docentes, núm. 4, 1986.

Maeder, Ernesto. "Los problemas de límites entre España y Portugal. Segunda parte, 1764-1809”, en Cuadernos Docentes, núm. 5, 1987.

Martins, Herbert. “A fragmentação do território brasileiro: a criação de novos estados no Brasil”, em Caderno CRH, núm. 35, 2001.

Navarro Floria, Pedro. "La nacionalización fallida de la Patagonia Norte, 1862-1904", en Quinto Sol, núm. 7, 2003.

Otero, Delia. "Articulación Estado-región de frontera en el área de Misiones o Palmas”, en Cuadernos de Historia. Serie Economía y Sociedad, núm. 5, 2002.

Schaller, Enrique. "El proceso de distribución de la tierra en la provincia de Corrientes (1588-1895)”, en Anuario del CEH, núm. 1, 2001.

Schmit, Roberto. "La construcción de la frontera decimonónica en la historiografía rioplatense", en Mundo Agrario, vol. VIII, núm. 16, 2008. 
Las disputas por los territorios en los albores del Estado nación: la frontera oriental...

Vitor Marcos Gregório. “A emancipação negociada: os debates sobre criação da província do Paraná e o sistema representativo imperial, 1843”, em Revista Brasileira de Historia, vol. XXXV, núm. 69, 2015.

\section{Tesis}

Freitag, Liliane. Extremo oeste paranaense: historia territorial, região, identidade e (re) ocupação, (tesis doctoral), Universidad Estadual Paulista, 2007.

Myskiw, Antonio. A fronteira como destino de viagem: a colônia militar da Foz do Iguaçu (1888-1907), (tesis doctoral), Universidad Federal Fluminense, 2009.

\section{Publicaciones en Internet}

Favaro, Orietta y Iuorno, Graciela (coords.). Dosier: Reflexiones en torno a los estudios sobre Territorios Nacionales, http://historiapolitica.com/dossiers/territorios/.

\section{Otros}

Allende, Andrés. "Las delimitaciones territoriales dispuestas por la ley de 5 de octubre de 1878", en Congreso Nacional de Historia sobre la Conquista del Desierto, General Roca, 1979.

Bressan, Raquel. "Los legisladores nacionales correntinos: trayectorias, vínculos y capacidad de negociación (1869-1880)", en IV Jornadas Interdisciplinarias de Investigaciones Regionales. Enfoques para la Historia, Universidad Nacional de Cuyo, 2015. 